\title{
The Bambuí Health and Aging Study (BHAS). Prevalence of Intermittent Claudication in the Aged Population of the Community of Bambuí and its Associated Factors
}

\author{
Valéria Maria de Azeredo Passos, Sandhi Maria Barreto Henrique Leonardo Guerra, \\ Josélia O liveira Araújo Firmo, Pedro Guatimosim Vidigal, Maria Fernanda Furtado Lima-Costa
}

Belo Horizonte, MG - Brazil

\begin{abstract}
Objective - To assess the prevalence of intermittent claudication in the aged population of Bambui, Brazil, and to identify the factors associated with this disease.

Methods - Population-based cross-sectional study of the aged population ( $\geq 60$ years of age) of Bambuí. Participants were interviewed and examined, after written consent. Intermittent claudication was defined based on a standardized questionnaire. Analysis was performed using multiple logistic regression.
\end{abstract}

Results - Of the 1,742 elderly living in Bambuí, 1,485 (85.2\%) were enrolled in the study. Thirty-seven individuals (2.5\%) with intermittent claudication were identified: 28 $(1.9 \%)$ males and $9(0.6 \%)$ females. Their age brackets were: $16(1.08 \%)$ individuals between 60 and 69 years of age, 17 $(1.15 \%)$ between 70 and 79 years, and $4(0.27 \%) \geq 80$ years. A significant association between intermittent claudication and the following characteristics was found: male $\operatorname{sex}($ OR=5.1; CI 2.4-11.0), smokers (OR=3.1; CI 1.2-8.5), exsmokers (OR=3.4; CI 1.3-8.7), andmore than 2 hospitaladmissions in the last 12 months (OR=2.8; CI 1.1-7.2).

Conclusion - Disease prevalence was similar to that of other countries. The association between intermittent claudication and smoking strengthens the significance of tobacco in peripheral artery disease pathogenesis. The association of intermittent claudication and a higher number of hospital admissions suggests greater morbidity in the elderly affected.

Key words: peripheral obstructive arterial disease, intermittent claudication, elderly, prevalence

Faculdade de Medicina da Universidade Federal de Minas Gerais Mailing address: Valéria Maria de Azeredo Passos - Av. Augusto de Lima 1715 30190-002 - Belo Horizonte, MG, Brazil - Email: vpassos@cpqrr.fiocruz.br English version by Stela Maris C. e Gandour
Diseases of the coronary arteries, brain, and peripheral arteries share atherosclerosis as their major cause. Atherosclerosis is a diffuse process, which may begin in infancy and slowly progress, culminating in the appearance of symptomatic ischemic syndromes, usually in adult life, mainly in the elderly. The vascular beds of different organs are affected, with clinical repercussions related to ischemic heart disease, stroke, renovascular disease, and peripheral artery diseases. The risk factors identified for the clinical syndromes related to atherosclerosis are classified as unmodifiable (age, male sex, and family history of atherosclerosis) and modifiable (tobacco use, sedentary lifestyle, diet rich in cholesterol and saturated fat, hypertension, obesity, hyperglycemia, high levels of LDL-cholesterol, and low levels of HDL-cholesterol) ${ }^{1}$.

Obstruction of arterial flow at the level of the abdominal aorta or femoral arteries, or both, depending on the severity of the clinical repercussion, may result in the following stages of arterial disease in the lower limbs: 1) asymptomatic or silent, diagnosed during complementary investigations of other processes, or through echocardiography ${ }^{2}$, or inferred due to an ankle-arm pressure index $<0.90^{3} ; 2$ ) symptomatic, defined as intermittent claudication; and 3) critical ischemic disease, with tissue necrosis or gangrene, or both ${ }^{4,5}$.

Intermittent claudication is a pathognomonic symptom of peripheral obstructive artery disease, which imposes important restrictions on activities of the elderly. Because it represents a diffuse atherosclerotic process, it is strongly associated with morbidity and mortality due to other cardiovascular diseases ${ }^{6}$. It is estimated that at least $10 \%$ of the patients with intermittent claudication have already had a cerebral stroke, and that $28 \%$ have coronary artery disease. Mortality rates in patients with intermittent claudication may be 2- to 3- times those seen in controls paired by sex and age, and $75 \%$ of the patients are estimated to die of a cerebrovascular or coronary event ${ }^{7}$. 
Because of the clinical relevance of this disease and the lack of data of population-based prevalence in Brazil, this study aimed to verify the prevalence of intermittent claudication in the elderly ( $\geq 60$ years of age) living in the town of Bambuí, in the State of Minas Gerais, Brazil, and to identify factors associated with this manifestation.

\section{Methods}

The Bambuí Heath and ageing project (BHAS) a population-based prospective study on ageing ${ }^{8}$. In our study, we analyzed data collected at baseline.

Bambuí is a town in Western Minas Gerais State, with approximately 20,000 inhabitants in 1996, 70\% of whom lived in the urban area of Bambuí. Cerebrovascular diseases constitute the major cause of death in the population aged $\geq 60$ years, followed by Chagas' and ischemic heart diseases. The high mortality due to Chagas' disease in this population results from its exposure, in the past, to infection by Trypanosoma cruzi; the transmission of the disease was interrupted 20 years ago ${ }^{9}$.

From November to December 1996, a census was conducted in Bambuí to identify the participants for the study. Of the 1,742 elderly ( $\geq 60$ years) living in the town of Bambuí, 1,494 (85.7\%) were interviewed and examined, and 1,485 $(85.2 \%)$ were enrolled in this study (no information regarding 1 or more items comprising the definition of intermittent claudication existed in 9 cases). After written consent, the interview was conduct in the dwelling by a trained interviewer and lasted approximately $90 \mathrm{~min}$. An elderly person who had any type of difficulty in answering the questionnaire was helped by a caretaker or a close relative (proxy).

The BHAS (Bambuí Health and Ageing Study) questionnaire, which was developed and previously tested by the project researchers, was used in the interviews, the following variables being considered: a) socio-demographic status; $b$ ) history of specific diseases (angina, infarction, osteoarthrosis, diabetes); c) lifestyles (physical activity, tobacco use, and alcohol ingestion): d) family history of cardiovascular diseases in individuals under the age of 50 years, and e) use of the health service.

Intermittent claudication was defined based on a standard World Health Organization ${ }^{10}$ questionnaire. It was considered probable when the interviewee reported pain in the calf during walking, which was not associated with the standing or sitting position, lasted up to 10 minutes, and disappeared with pace reduction or interruption of the gait. The interviewees reporting that the pain did not disappear with interruption of the gait were classified as having possible intermittent claudication (chart I).

Physical measurements and laboratory examinations were performed in the Emmanuel Dias health center of the Fundação Oswaldo Cruz, or in the dwelling, when a debilitating health factor existed. Blood pressure was measured with the patient in the sitting position, after a rest of at least $5 \mathrm{~min}$, with the arm level with the heart; no caffeine or tobacco could have been used in at least the previous 30min. Three blood pressure measurements were taken with intervals of at least $2 \mathrm{~min}$; the first measurement was discarded, and the blood pressure used in the study was the mean of the last 2 measurements ${ }^{11}$. Systemic hypertension was defined as blood pressure $\geq 140 / 90 \mathrm{mmHg}$ or use of an antihypertensive medication, which was examined in its original package by the interviewer, or both ${ }^{11}$.

The anthropometric indicator used was body mass index $\left(\mathrm{BMI}=\right.$ weight $/$ height $\left.^{2}\right)$, and the measurements were taken by trained personnel, using standard equipment (CMS Weighing Equipment Ltd, Co.).

Blood samples were collected after the study participant had fasted for 12 hours for biochemical tests (glucose, urea, creatinine, total cholesterol and its fractions, and triglycerides) and serological tests for Chagas' disease (indirect hemagglutination and ELISA Biolab and Abbott Brasil).

Many questions of the BHAS questionnaire had previously codified responses. The questionnaires were typed with double entry and checked for errors. The results of the biochemical parameters were directly input into an appropriate software program.

All data were stored in dbf files and analyzed with Stata Statistical Software ${ }^{12}$. The factors associated with intermittent claudication were assessed using multiple logistic regression ${ }^{13}$. In multivariate analysis, the following criteria of inclusion in the logistic model were used: a) level of association between independent variables and intermittent claudication below $20 \%(\mathrm{p}<0.20)$; and $\mathrm{b})$ variables that, even not having an association at this level, could be potential confounders (sex, age, and close responder). In the final model, we considered all variables associated with intermittent claudication that had a $\mathrm{p}$ value for the similarity ratio equal to or below 0.05 . The power of associations between variables in uni- and multivariate analyses was determined by odds ratio (OR) and their confidence intervals $(\mathrm{CI})$ calculated by the Woolf method ${ }^{13}$.

\section{Results}

Of the 1,485 elderly persons interviewed, $37(2.5 \%)$ met the criteria for probable intermittent claudication. Twentyeight $(1.9 \%)$ were males and $9(0.6 \%)$ were females; 16 $(1.08 \%)$ were between 60 and 69 years of age, $17(1.15 \%)$ between 70 and 79 years, and $4(0.27 \%)$ were 80 years of age or above. The prevalence of intermittent claudication according to sex and age group shows a predominance of intermittent claudication in the male sex, with a higher concentration in the age range from 70 to 79 years, and a significant drop in the age range $\geq 80$ years (fig. 1 ). Only 1 participant met the criteria for possible intermittent claudication, and his exclusion from the statistical analysis changed neither the associations found nor their force or direction. Therefore, we chose to analyze only the individuals with probable intermittent claudication.

In univariate analysis, intermittent claudication was associated with male sex, age between 70 to 79 years, fre- 


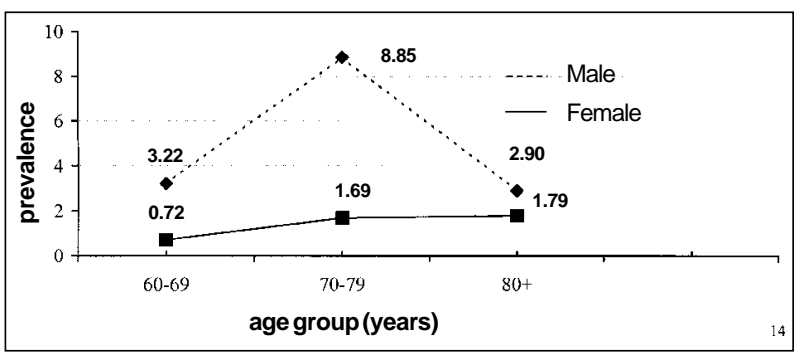

Fig. 1 - Prevalence of intermittent claudication in the elderly population of Bambuí, according to sex and age group.

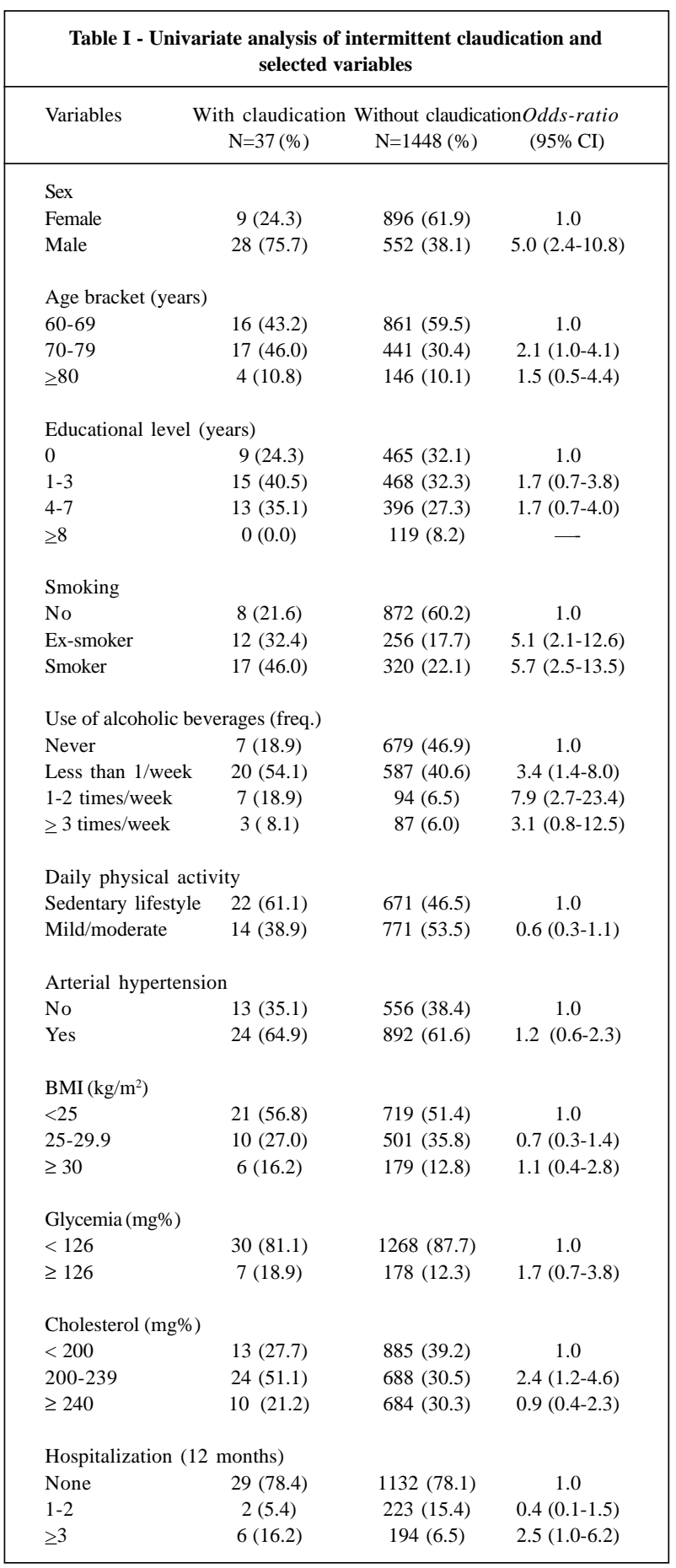

quency of ingestion of alcoholic beverages, current or past tobacco use, a higher number of hospitalizations in the last 12 months, and cholesterol levels between 200 and $239 \mathrm{mg} /$ $\mathrm{dL}$ (tab. I). After adjustment for the multivariate analysis, only male sex, tobacco use, and a higher number of hospitalizations in the last year remained statistically associated with intermittent claudication (tab. II).

In regard to the presence of other cardiovascular diseases, $10(27.0 \%)$ of 37 elderly with intermittent claudication reported at least 1 concomitant cardiovascular disease: 5 reported a medical diagnosis of angina pectoris; 4 reported a previous episode of myocardial infarction; and 1 reported 1 previous episode of cerebral stroke. However, the occurrence of these other cardiovascular diseases was not statistically associated with intermittent claudication in the present study.

Six elderly with intermittent claudication reported a medical diagnosis of diabetes mellitus, but no association was found between intermittent claudication and the medical diagnosis of diabetes $(\mathrm{OR}=1.4$; $\mathrm{CI} 0.6-3.6)$ or with hyperglycemia $(\mathrm{OR}=1.7$; $\mathrm{CI}$ (confidence internal) 0.7-3.8).

Six $(16.2 \%)$ of the 37 elderly with intermittent claudication and 363(25.1\%) of the 1,448 elderly withoutintermittentclaudication had positive serology for Trypanosoma cruzi, which is a statistically nonsignificant difference $(\mathrm{OR}=0.6 ; \mathrm{CI} 0.2-1.4)$.

\section{Discussion}

Studies carried out in developed countries show that the incidence of intermittent claudication increases with age. For a male under the age of 50 years, the prevalence is around $1-2 \%$; for another above 50 years of age, the prevalence increases to $5 \%{ }^{5}$. A similar tendency is observed for females, with lower values, however ${ }^{5}$. In the elderly population of Bambuí, the prevalence of intermittent claudication according to sex and age was similar to that reported in international epidemiological studies; no population-based

\begin{tabular}{|c|c|c|c|}
\hline \multicolumn{4}{|c|}{$\begin{array}{l}\text { Table II - Variables associated with intermittent claudication in } \\
\text { multivariate analysis }\end{array}$} \\
\hline Variables & \multicolumn{3}{|c|}{$\begin{array}{l}\text { With claudication Without claudication Adjusted } \\
\text { odds ratio \# } \\
\qquad \begin{array}{l}\mathrm{N}=37(\%) \quad \mathrm{N}=1448(\%) \\
\text { (CI 95\%) }\end{array}\end{array}$} \\
\hline \multicolumn{4}{|l|}{ Sex } \\
\hline Female & $9(24.3)$ & $896(61.9)$ & 1.0 \\
\hline Male & $28(75.7)$ & $552(38.1)$ & $5.1(2.4-11.0)$ \\
\hline \multicolumn{4}{|l|}{ Smoking } \\
\hline No & $8(21.6)$ & $872(60.2)$ & 1.0 \\
\hline Ex-smoker & $12(32.4)$ & $256(17.7)$ & $3.1(1.2-8.5)$ \\
\hline Smoker & $17(46.0)$ & $320(22.1)$ & $3.4(1.3-8.7)$ \\
\hline \multicolumn{4}{|c|}{ Hospitalization (12 months) } \\
\hline None & $29(78.4)$ & $1132(78.1)$ & 1.0 \\
\hline $1-2$ & $2(5.4)$ & $223(15.4)$ & $0.4(0.1-1.8)$ \\
\hline$\geq 3$ & $6(16.2)$ & $194(6.5)$ & $2.8(1.1-7.2)$ \\
\hline
\end{tabular}


studies of prevalence have been conducted in our country. The higher prevalence of intermittent claudication in males in the age group from 70 to 79 years probably reflects only a lower survival of the elderly with intermittent claudication above the age of 80 years, because intermittent claudication is associated with higher mortality due to other cardiovascular diseases ${ }^{6}$. It is worth noting that in the data analysis of a probabilistic sample of the adult population (18-59 years) of the community studied, the prevalence of intermittent claudication was significantly lower $(1.22 \%, \mathrm{p}=0.04)$ (BHAS, unpublished data) and also close to the values found in other studies with an adult population ${ }^{6}$.

In population inquiries, the evaluation of symptoms provides a potentially significant measure of diseases at a low cost. In our study, the definition of intermittent claudication was based on a questionnaire widely used and assessed in other countries ${ }^{10}$. Intermittent claudication may be presumed if the patient experiences a clinical ischemic event, even if this event has not been confirmed by other diagnostic techniques ${ }^{14}$. However, intermittent claudication represents only the symptomatic cases of peripheral artery disease, whose prevalence was estimated as at least 3 times higher with the use of sensitive and noninvasive techniques ${ }^{5,15}$.

In accordance with our data, the relation between smoking and intermittent claudication has been consistently documented in several studies ${ }^{6,16}$. Smoking is considered a more important risk factor for peripheral obstructive artery disease than for coronary artery disease ${ }^{17}$. Smoking is associated with the following: lower absorption of antioxidant vitamins from the diet, higher ingestion of alcoholic beverages, lower levels of HDL-cholesterol, higher diastolic pressure, hypertriglyceridemia, higher blood viscosity, and a higher concentration of markers for endothelial disorders (tissue plasminogen activator and the von Willebrand antigen $)^{16}$. The association with this potentially modifiable risk factor reveals the importance of programs aiming at the positive change in lifestyles to improve the physical condition of the elderly affected and the prevention of new cases of intermittent claudication. The fact of finding aged individuals with intermittent claudication, who still continue to smoke, emphasizes the importance of diagnosing the disease and encouraging smoking cessation to improve the prognosis of these cases.

Longitudinal studies provide epidemiological evidence of the association between intermittent claudication and systemic hypertension, hypercholesterolemia, and hyperglycemia ${ }^{5,18}$. In the present study, associations between intermittent claudication and these factors were not evident, not even between intermittent claudication and stages 3 and 4 of systemic hypertension (blood pressure $\geq 160 / 100 \mathrm{mmHg}){ }^{17}$. Nevertheless, a higher proportion of cases of intermittent claudication with hypertension in these stages is observed than in the cases with no intermittent claudication $(24 \% \times 19 \%)$, without a statistically significant difference ( $\mathrm{p}=0.142)$. Our study has a cross-sectional design and analyzes data of the aged population of a community. These two factors increase the possibility of the occurrence of survival bias, i.e. the elderly identified with intermittent claudication in this study represent the individuals who survived other diseases, atherosclerosis included, and its major risk factors (arterial hypertension, dyslipidemia, and hyperglycemia). In addition, the high prevalence (>60\%) of some risk factors for atherosclerosis (sedentary lifestyle, arterial hypertension, and hypercholesterolemia), added to the low prevalence of the phenomenon studied $(<3 \%)$, may have decreased the capacity to detect a possible association between these variables.

The association between intermittent claudication and a higher number of hospitalizations may be an indicator of greater morbidity in the elderly with intermittent claudication. Another indicator of morbidity is the fact that, of the 37 aged individuals with intermittent claudication, 10 (27\%) reported another cardiovascular event, which suggests the presence of diffuse atherosclerosis ${ }^{19}$. The clinical relevance of this finding is that patients with diffuse atherosclerosis have a higher risk of cardiovascular mortality and a worse quality of life than those patients with only 1 atherosclerotic event ${ }^{20}$.

In the Bambuí project, all efforts were concentrated on avoiding bias: the rate of participation in the study was hi$\mathrm{gh}$, the procedures and instruments used were tested and standardized, and the field and laboratory teams received intensive training before beginning the study. When compared, the participants in this study were similar to the population of the town in regard to sex, age, marital status, monthly family income, and educational level, confirming the internal representativeness and validity of the data obtained $^{8}$. However, we cannot exclude the possibility of a sampling error in classifying the cases as with and without intermittent claudication, which tends to approximate the odds ratio to 1.0, i.e., nonexistence of an association.

In summary, atherosclerosis of peripheral arteries in the

\begin{tabular}{|c|c|c|}
\hline \multicolumn{3}{|c|}{$\begin{array}{c}\text { Chart I - Questions used in the definition of intermittent clau- } \\
\text { dication }\end{array}$} \\
\hline \multicolumn{3}{|c|}{ Structured questions of the BHAS* questionnaire } \\
\hline \multicolumn{3}{|c|}{ 1. Do you feel any pain in your leg when you walk? } \\
\hline \multicolumn{3}{|c|}{ 2. Does this pain appear when you are standing or sitting? } \\
\hline \multicolumn{3}{|c|}{ 3. In which part of your leg do you feel the pain? } \\
\hline $\begin{array}{l}\text { a) } \mathbf{\square} \text { calf } \\
\text { included }\end{array}$ & $\begin{array}{l}\text { b) } \square \text { calf not } \\
\text { included }\end{array}$ & c) $\square \mathbf{N A}$ \\
\hline \multicolumn{3}{|c|}{ 4. Does your leg ache when you go up a slope or run? } \\
\hline 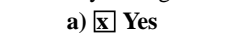 & b) $\square$ No & c) $\square$ NA \\
\hline \multicolumn{3}{|c|}{ 5. Does the pain always subside when you walk? } \\
\hline a) $\square$ Yes & b) $\mathbf{x}$ No & c) $\square$ NA \\
\hline \multicolumn{3}{|c|}{ 6. What do you do when this pain appears? } \\
\hline $\begin{array}{l}\text { a) } \mathbf{~} \text { stop/reduce } \\
\text { your pace }\end{array}$ & $\begin{array}{l}\text { b) } \square \text { continue at } \\
\text { the same pace }\end{array}$ & c) $\square$ NA \\
\hline \multicolumn{3}{|c|}{ 7. What happens to the pain in your leg when you stand still? Does it disappear? } \\
\hline a) $\mathbf{x}$ Yes & b) $\square$ No & c) $\square \mathbf{N A}$ \\
\hline \multicolumn{3}{|c|}{ 8. How long does the pain take to disappear? } \\
\hline a) $\mathbf{x} \leq 10 \mathrm{~min}$ & b) $\square \geq 10 \mathrm{~min}$ & c) $\square \mathbf{N A}$ \\
\hline
\end{tabular}


aged population of Bambuí showed a frequency similar to that reported in developed countries, and males above the age of 70 years had a higher risk of becoming ill. Smoking was the major factor associated with intermittent claudication, and the elderly with intermittent claudication had a tendency toward a higher frequency of sedentary lifestyles, arterial hypertension, and hypercholesterolemia than the elderly without this manifestation. However, many unknown points still exist in regard to the risk factors for intermittent claudication, which were considered identical to those of other cardiovascular diseases ${ }^{21}$. The incidence, risk factors, and prevention of angina, infarction, and cerebral stroke have been more and better studied than has intermittent claudication, which is the major manifestation of peripheral artery disease ${ }^{19}$, both in Brazil and in other countries. One reason for this discrepancy may be the more dramatic clinical findings of coronary artery disease and cerebral stroke, which frequently lead to death ${ }^{19}$. Further population-based studies are fundamental for the delineation of the actual dimension of this problem in the elderly Brazilian population.

\section{References}

1. Chang MY, Chait A. Atherosclerosis and ageing. In: Hazzard WR, Blass JP, Ettinger Jr WH, Halter JB, Ouslander JG. Principles of Geriatric Medicine and Gerontology. $4^{\text {th }}$ ed., 1999: 61-8.

2. Simon A, Segond P, Giard AM, Demure B, Gitel R, Levenson J. Diagnostic précoce de l'athérosclérose silencieuse et dépistage des facteurs de risque cardiovasculaire. Presse Méd 1993, 22: 1033-8.

3. Fowkes FGR, Housley E, Cawood EHH, et al. Edinburg Artery Study: prevalence of assymptomatic and symptomatic peripheral arterial disease in the general population. Int J Epidemiol 1991; 20: 384-92.

4. Sécond document de consensus européen sur l'ischémie critique périphérique. J Mal Vasc 1992; 17(supl.): 138-71.

5. Weitz JI, Byrne J, Clagett GP, et al. Diagnosis and treatment of chronic arterial insufficiency of the lower extremities: a critical review. Circulation 1994; 94 : 3026-49.

6. Smith GD, Shipley MK, Rose G. Intermittent claudication, heart disease factors and mortality. The Whitehall Study. Circulation 1990; 82: 1925-31.

7. Kannel WB, McGee DL. Update on some epidemiologic features of intermittent claudication: the Framingham Study. J Am Geriatr Soc 1985; 33: 13-8.

8. Lima e Costa MFF, Uchoa E, Guerra HL, Firmo JOA, Vidigal PG, Barreto SM. The Bambuí health and ageing study (BHAS): methodological approach and preliminary results of a population-based cohort study of the elderly in Brazil. Rev Saúde Pública 2000; 34: 126-35.

9. Lima e Costa MFF, Barreto SM, Guerra HL, Firmo JOA, Uchoa E, Vidigal PG Ageing with Trypanosoma cruzi infection in a community where the transmission has been interrupted: the Bambuí Health and Ageing Study (BHAS). Int J Epidemiol 2001 (no prelo).

10. Rose GA. The diagnosis of ischaemic heart pain and intermittent claudication in field surveys. Bull WHO 1962; 27: 645-58.
11. JNC 1993. The fifth report of the Joint National Committee on Detection, Evaluation, and Treatment of High BP. Arch Int Med 153: 154-83.

12. Stata Statistical Software (computer program). Release 6.0 College Station, Texas: Stata Corporation, 1997.

13. Hosmer DW, Lemenshow S. Applied Logistic Regression. New York: Johns Wiley and Sons; 1989.

14. Gardner AW. Peripheral vascular disease. In: Hazzard WR, Blass JP, Ettinger Jr WH, Halter JB, Ouslander JG. Principles of Geriatric Medicine and Gerontology. $4^{\text {th }}$ ed., 1999: 705-12.

15. Newman AB, SiscovickDS, Manolio TA, et al. Ankle-armindex as a marker of atheroscerosis in the Cardiovascular Health study. Circulation 1993; 88: 837-45.

16. Price JF, Mowbray PI, Lee AJ, Rumley A, Lowe GD, Fowkes FG. Relationship between smoking and cardiovascular risk-factors in the development of peripheral arterial disease and coronary arteries disease: Edinburgh Artery Study. Eur Heart J 1999; 20: 344-53.

17. Gordon T, Kannel WB. Predisposition to atherosclerosis in the head, heart and legs: the Framingham Study. JAMA 1972; 221: 661-6.

18. Murabito JM, D'Agostino RB, Silbershastz H, Wilson PWF. Intermittent claudication. A risk profile from the Framingham Heart Study. Circulation 1997; 96: 44-9.

19. Meco JF, Pintó X, Escribà JM, Vela M, et al. Cardiovascular risk factors associated with clinically isolated and diffuse atherosclerosis in Spanish patients with coronary artery disease. Eur J Clin Invest 1998; 28: 643-50.

20. Wilt TJ, Rubbins HB, Collins D, Oçonnor TZ, Rutan GH, Robins SJ. For the Veterans Affairs High-Density Lipoprotein Intervention Trial Study group. Correlates and consequences of diffuse atherosclerosis in men with coronary heart disease. Arch Intern Med 1996; 156: 1181-8.

21. Bowlin SJ, Medalie JH, Flocke AS, Zyzanski SJ, Goldbourt U.Epidemiology of intermittent claudication in middle-aged men. Am J Epidemiol 1994; 140: 418-30 